\section{Decálogo de la conducta ética del servicio de camillería. Extendiendo la bioética}

\section{Decalogue of the ethical conduct of the stretcher service. Extending bioethics}

\author{
José Luis Sandoval-Gutiérrez* \\ *Instituto Nacional de Enfermedades \\ Respiratorias Ismael Cosío Villegas. \\ Ciudad de México, México.
}

Citar como: Sandoval-Gutiérrez JL. Decálogo de la conducta ética del servicio de camillería. Extendiendo la bioética. Neumol Cir Torax. 2021; 80 (3): 237. https://dx.doi.org/10.35366/102574

Existe la obligatoriedad en los hospitales de mostrar las cartas de los derechos de los pacientes, enfermeras y los médicos. ${ }^{1-3}$

Es importante involucrar a otras áreas de servicio de atención médica que tienen una participación importante en el adecuado manejo de los pacientes.

Camillería es el departamento que está involucrado en la atención directa de todos los casos de un nosocomio, en muchas ocasiones es la primera y última imagen de un hospital, es necesario la participación de las personas que pertenecen al mismo en los tópicos de ética y bioética, la búsqueda obligada en libros, revistas e internet no provee de herramientas para este fin.

En el Instituto Nacional de Enfermedades Respiratorias Ismael Cosío Villegas (INER) nos dimos a la tarea en el Comité de Bioética Hospitalaria, en alianza con el personal del mencionado servicio, de atender esta necesidad, revisamos los principales tópicos éticos necesarios para un buen desempeño en sus actividades diarias, las expresiones y opiniones de cada uno de los participantes nutrieron enormemente esta propuesta, se realizó un consenso de las características, el cual fue distribuido para comentarios y mejoras en el servicio, toda esta actividad tuvo la necesidad de un tiempo de tres meses.

Esta iniciativa sin antecedente ha logrado la satisfacción y autorización del Comité de Ética (oficio institucional INER/CHB/007/2018), además del apoyo y compromiso de cumplimiento por parte del recurso humano involucrado.

Una medida para adecuar la participación de este grupo paramédico es darle la connotación moral y ética de su trabajo, prácticamente no existe un código en especial de los sujetos encargados en el adecuado traslado de los enfermos en el ámbito hospitalario, al no tener este recurso, se decidió crear el mismo junto con el personal involucrado en esta actividad, resultando lo siguiente:

La observancia del código de ética, para el personal de camillería nos compromete a:

1. Respetar la vida y derechos humanos, manteniendo una conducta honesta y leal en el cuidado de las personas.

2. Proteger la integridad de los individuos ante cualquier afectación, otorgando los cuidados en la movilización y traslado, aplicando las técnicas requeridas.

3. Mantener una relación estrictamente profesional con las personas que atiende, sin distinción xenófoba, racista, elitista, sexista, religiosa, social, política, o bien, por naturaleza de enfermedad.

4. Asumir la responsabilidad como parte de los miembros del equipo de salud, enfocados en los cuidados de la movilización y traslado, para la conversión de la salud y prevención del daño.

5. Guardar el secreto profesionalmente, observando los límites del mismo, ante riesgo o daño a la propia persona y/o terceros.

6. Procurar que el entorno laboral sea seguro tanto para las personas, sujeto de la atención del camillero, como para quienes conforman el equipo de salud.

7. Evitar la competencia desleal, compartiendo con estudiantes y colegas experiencias y conocimientos en beneficio de las personas y de la comunidad hospitalaria.

8. Asumir el compromiso responsable de actualizar y aplicar los conocimientos científicos y humanísticos de acuerdo con su competencia profesional.

9. Pugnar por el desarrollo de la profesión y dignificar su ejercicio.

10. Fomentar la participación y el espíritu de grupo para lograr los fines como profesional de la salud.

La relación médico-paciente tiene cada vez más actores para el adecuado resultado terapéutico (nutriología, fisioterapia, inhaloterapia, administración, vigilancia, intendencia, etcétera).

El hacer consciente a todas estas personas de su relevancia y el comportamiento necesario para el adecuado resultado permitirá una mejor sintonía de acción en esta dualidad.

Este código cuenta con la anuencia del comité de bioética del instituto para darle difusión intrahospitalaria, además se permite que el mismo se promueva a otras unidades hospitalarias.

El servicio de camillería tradicionalmente no ha sido valorado en su necesaria intervención para el proceso de mejora del paciente, es necesario empoderar y reconocer esta gran labor, también es importante impulsar estas actividades para profesionalizar al personal y mejorar el trato en beneficio de los pacientes.

\section{REFERENCIAS}

1. Carta de los derechos generales de los pacientes. Secretaría de Salud. Rev de la Asoc Mex de Med Crit y Ter Int. 2002;16(5):170-172.

2. Carta de derechos generales de las Enfermeras y los Enfermeros. Disponible en: https://salud. edomex.gob.mx/ccamem/carta_derechos generales

3. Carta de los derechos generales de los Médicos. Disponible en: https://salud.edomex.gob.mx/ ccamem/carta_derechos_medicos

Correspondencia:

Dr. José Luis Sandoval-Gutiérrez Instituto Nacional de Enfermedades Respiratorias Ismael Cosío

Villegas, Ciudad de México.

Correo electrónico:

sandovalgutierrez@gmail.com

Conflicto de intereses: El autor declara no tener conflicto de intereses. 